\title{
Arquitetura da Informação para ambientes informacionais digitais
}

\section{Information Architecture: for the web and beyond}

Angela Maria Grossi de Carvalho

Universidade Estadual Paulista Júlio de Mesquita Filho (Unesp), Marília, SP, Brasil.

ORCID: 0000-0002-5425-4917

<angela@carvalho.jor.br>
Maira Nani França

Universidade Estadual Paulista Júlio de Mesquita Filho

(Unesp), Marília, SP, Brasil.

ORCID: 0000-0002-7636-8966

<mairanani@hotmail.com>

\section{RESUMO}

Resenha de: ROSENFELD, Lou; MORVILLE, Peter; ARANGO, Jorge. Information Architecture: for the Web to beyond. Sebastopol/Califórnia: O'Reilly Media, 4. ed., 2015.

A primeira edição do livro Information Architecture: for the World Wide Web foi publicada em 1998. Naquela época não se falava em Web 2.0 e Redes Sociais como o Facebook; não havia tanta variedade de dispositivos móveis com múltiplas funcionalidades, que não somente permitem a realização e o recebimento de chamadas telefônicas e, termos como Folksonomia e Internet das Coisas não tinham sequer sido criados. "O caos da impermanência altera o mundo a nossa volta"1 (Rosenfeld; Morville; Arango, 2015, p. xiii, tradução nossa). O crescimento exponencial de informações advindos com a criação da internet, na década de 1990, tem impulsionado a busca constante de soluções para agilizar a recuperação da informação, de modo que seja mais fácil navegar e, consequentemente, encontrar o que deseja. A nova geração da sociedade da informação, "24x7", que cada vez mais manipula a informação com leves toques nas telas de seus smartphones, tablets, e-readers, relógios inteligentes, dentre outros dispositivos, anseia conectividade 24 horas por dias, 7 dias da semana, em todo e qualquer ambiente, a todo momento.

Nesse contexto, considerando principalmente os múltiplos canais de interação entre os indivíduos, em outubro de 2015 foi publicada a quarta edição do livro Information Architecture, com um novo subtítulo for the Web to beyond (486 p.). Os novos produtos e serviços digitais exigem padrões que

1 "The chaos of impermanence alters the world around us". 
promovam sua coerência, consistência e compreensão, independentemente de sua manifestação no espaço e no tempo. "A mudança é implacável, onipresente, emocionante - e um pouco assustadora"2 (Rosenfeld; Morville; Arango, 2015, p. xii, tradução nossa). Essa edição apresenta conceitos, métodos e técnicas de design digital aos designers e desenvolvedores, orientando-os na criação de estruturas semânticas, a partir da experiência do usuário em um contexto mais complexo, com ampla aplicabilidade para além do design da web convencional, tornando o conteúdo mais consistente, coerente, fácil de ser encontrado e compreensível.

A obra é composta por treze capítulos, divididos em três partes: Apresentando a Arquitetura da Informação (pt. 1, cap. 1-4), Princípios básicos da Arquiteturadalnformação (pt.2,cap.5-10) eAplicaçãodaArquiteturadalnformação (pt. 3, cap. 11-13) e é finalizado com uma parte conclusiva, denominada Coda, que recapitula o que foi apresentado, apontando o que está por vir e com um Apêndice que indica outros livros na área que podem aprimorar mais a prática, além de listar as organizações profissionais consideradas referência em Arquitetura da Informação nos dias atuais e um Índice de Assunto/Autor. Cada capítulo é finalizado com uma seção de recapitulação que aborda os principais pontos tratados.

A parte 1 da nova edição de Rosenfeld, Morville e Arango intitulada Apresentando a Arquitetura da Informação oferece uma ampla visão da Al tanto para os novos profissionais da informação quanto para aqueles que apresentam expertise na área.Em Problemas referentes à Al(Cap. 1) são descritos o cenário atual e os principais desafios para lidar com o complexo ambiente informacional. Em nosso tempo, a informação é mais abundante do que nunca e temos inúmeras maneiras de interagir com ela, como nunca foi vivenciado. Este excesso tem estimulado a criação de novas tecnologias para auxiliar as pessoas a organizar, encontrar e fazer melhor uso da informação, em uma ampla variedade de contextos físicos e psicológicos. Historicamente a informação tem mostrado uma tendência a se desmaterializar, passando de um relacionamento de umpara-um com seus formatos (dispositivos) para ser completamente separada de seus invólucros (como é o caso da informação digital). Neste contexto a Al é tratada pelos autores como uma disciplina focada em tornar os ambientes informacionais encontráveis e compreensíveis, funções estas que se relacionam mesmo apresentando objetivos distintos. O profissional da informação (designer) que atua nesta área deve pensar os problemas por intermédio de duas perspectivas importantes: a) produtos e serviços são percebidos como

2 "Change is relentless, ubiquitous, exhilarating - and a little scary". 
lugares feitos de informações e b) funcionam como ecossistemas que podem ser concebidos para o máximo de eficácia. Segundo os autores, a Al não opera exclusivamente no nível de abstrações. Para que ela seja eficaz, precisa ser definida em vários níveis, sendo necessário uma abordagem sistemática e abrangente que facilite a encontrabilidade da informação e seu entendimento, independentemente do conteúdo, canal ou meio que o usuário utiliza para acessá-la.

No capítulo 2, Definindo $A \beta$, são apresentadas definições e analogias à Al, bem como é apontada a dificuldade de identificá-la na vida cotidiana. A Al pode ser entendida como um "projeto estrutural de ambientes informacionais compartilhados", "a síntese dos sistemas de organização, rotulagem, busca e navegação em ecossistemas digitais, físicos e híbridos", "a arte e ciência de moldar produtos e experiências informacionais como apoio à usabilidade, encontrabilidade e compreensão da informação" e ainda, "uma disciplina emergente e uma comunidade prática focadas nos princípios do desenho e arquitetura da paisagem digital"4 (Rosenfeld; Morville; Arango, 2015, p. 24, tradução nossa). A Al é principalmente abstrata, localizada abaixo da superfície nas estruturas semânticas de produtos e serviços de informação. A base do modelo apresentado pelos autores para a prática eficaz do design da Al considera três elementos interdependentes: usuários ${ }^{5}$, contexto ${ }^{6}$ e conteúdo ${ }^{7}$, cuja relação compõem o conceito de "ecologia da informação" que visa resolver as dependências complexas existentes nos ambientes informacionais. A combinação específica de variáveis não muda apenas de um ambiente informacional para outro, mas também em um único ambiente informacional ao longo do tempo.

O capítulo 3, Design para encontrar, auxilia o leitor na melhor compreensão das necessidades e dos comportamentos das pessoas. A Al surge da necessidade das pessoas por informação e da razão pela qual elas utilizam determinados serviços e produtos. A meta mais importante para se projetar a Al

3 No final do capítulo 1 os autores destacam que "Definning the Damage Thing" (DTDT) é uma fonte contínua de discórdia na comunidade da Al e alertam que ao se rotular coisas, disputas sobre os limites conceituais passam a ser um risco ocupacional (Rosenfeld; Morville; Arango, 2015, p. 22, destaque nosso).

4 "An emerging discipline and community of practice focused on bringing principles of design and architecture to the digital landscape".

5 Pessoas, seres humanos com desejos, necessidades, preocupações, fraquezas (audiência, tarefas, demandas, comportamento da busca da informação, experiência).

6 Capacidades, aspirações e recursos únicos de cada organização (objetivos do negócio, financiamento, política, cultura, tecnologia, recursos e restrições).

7 Documentos, aplicações, serviços, esquemas que as pessoas precisam utilizar ou encontrar em determinado sistema (tipo de documento/dado, propriedade, formato, estrutura, metadados, volume, dinamismo). 
é a satisfação das necessidades das pessoas. Que tipo de informação os usuários precisam? O quanto de informação é suficiente? Como eles interagem com a arquitetura? Existem diferentes modelos que retratam o que acontece quando as pessoas procuram uma informação. O mais simples deles (Too-Simple) ${ }^{8}$ é o mais problemático, uma vez que não representa o que realmente acontece quando as pessoas têm determinada necessidade de informação. É muito comum a pessoa não saber exatamente o que está procurando. Geralmente, as pessoas apresentam comportamento variado na busca de informação para satisfazer suas necessidades de um modo amplo e genérico em vez de específico. As quatro necessidades informacionais mais comuns são a busca exaustiva (todas as coisas), busca exploratória (poucas coisas boas), busca por um item conhecido (a coisa certa) e novas demandas (refinamento). Neste capítulo os autores afirmam que existem vários métodos de pesquisa que permitem a compreensão dos comportamentos da busca de informação, como consultas em sistemas de buscas, navegação em links e solicitação de ajuda por e-mail, chats e interfaces. A análise da pesquisa (grande volume dos dados reais dos usuários) e a investigação contextual (interação dos usuários com as informações em seus ambientes naturais) são instrumentos que auxiliam na compreensão da necessidade informacional dos usuários e do comportamento da busca.

Os contextos ideais para as pessoas compreenderem a informação por meio da Al são apresentados no capítulo 4, denominado Design para compreender. A estrutura dos ambientes informacionais influencia além do modo que as coisas são encontradas, ela também altera a forma em que cada objeto é compreendido. Os ambientes informacionais são experimentados como lugares onde as pessoas tratam, aprendem e se conectam com outras pessoas, dentre outras atividades. Alguns ambientes informacionais são criados principalmente para permitir que as pessoas interajam e socializem com outras, como as redes sociais, por exemplo. Ao projetar ambientes de informação aprende-se com o design de ambientes físicos, cujos princípios de organização incluem: estrutura e ordem, ritmo, tipologias, modularidade e extensibilidade. A maneira como um ambiente informacional é compreendido - o contexto que define suas informações influencia no modo em que as informações são encontradas nele, e vice-versa. A maioria dos ambientes informacionais é dinâmico e efêmero, enquanto suas estruturas semânticas permanecem relativamente estáveis, seu design visual (layout e mecanismos de interação) pode mudar

8 a) o usuário faz uma pergunta; b) algo acontece (busca ou navegação) e c) o usuário recebe a resposta. O usuário quer a resposta certa para a sua pergunta. 
consideravelmente ao longo de um período. Para Rosenfeld, Morville e Arango (2015) a estrutura organizacional do ambiente é um fator crítico para influenciar a forma como as pessoas entendem o que podem fazer nele e as informações que esperam encontrar e produzir quando dele participam.

Os capítulos inseridos na parte 2, denominada Princípios básicos da $A l$, tratam dos componentes essenciais de uma arquitetura que ilustra sua natureza interconectada e que possibilitam que a Al alcance seus objetivos, como apresentado a seguir. Uma Al bem projetada é invisível para os usuários. Em Anatomia de uma Al, capítulo 5, é possível visualizar cada elemento da arquitetura. Apresenta, ainda, uma introdução dos sistemas abordados nos capítulos sequenciais. Uma das características apontadas no início deste capítulo é a aplicação do design responsivo, que demonstra que um site pode ser visto de diferentes formas e contextos. $O$ design responsivo responde ao tamanho da tela para se adequar da melhor forma conforme o equipamento de leitura. Dentre as diversas maneiras de categorizar os componentes da Al, os autores destacam quatro maneiras básicas em que a informação é estruturada: sistemas de organização (apresentam a informação do site), sistemas de navegação (auxiliam os usuários a se moverem através do conteúdo), sistemas de busca9 (permitem que os usuários pesquisem o conteúdo) e sistemas de rotulagem (descrevem categorias, opções e links na linguagem que é significante para os usuários), tratados especificamente nos capítulos a seguir. A Al de cima para baixo (Top-Down), partindo do geral para o específico, postula uma estrutura que visa responder perguntas dos usuários como: Onde estou? Sei o que eu estou procurando? Como faço para procurar? Como faço para navegar neste site? O que é importante e única sobre sua organização? O que está disponível? O que está acontecendo? Como faço para interagir com ele em outros canais digitais? Como entro em contato com uma pessoa? Qual é o seu endereço? Como acesso minha conta? Por meio dos sistemas de busca e navegação a estrutura inerente ao conteúdo, de baixo para cima (Bottom-Up), partindo do específico para o geral, permite respostas às perguntas dos usuários para "subir" para a superfície: Onde estou? O que tem aqui? Para onde posso ir a partir daqui? Como alternativas para categorizar os componentes da Al, além dos sistemas que serão tratados nos capítulos seguintes, os autores apresentam os auxiliares de navegação (sistema de organização - taxonomias e hierarquias,

9 Apesar de o livro não apresentar explicitamente, destaca-se uma quinta categoria dos componentes da Al denominada Sistema de Representação, que engloba os elementos que controlam o vocabulário (tesauro, vocabulário controlado e metadados), tratados no capítulo 10 do livro em questão, perpassando os demais sistemas. Nota elaborada a partir das discussões realizadas na disciplina Arquitetura da Informação Digital ministrada pela prof. Silvana Vidotti (PPGCI/UNESP), de 3 a 9 de julho de 2016. 
sistemas de navegação geral e local, mapas de site/tabelas de conteúdo, índices, guias, passo-a-passo e assistentes e, sistema de navegação contextual), auxiliares de busca (interface de busca, linguagem de consulta - operadores booleanos, por proximidade e específicos, construtores de consultas, algoritmos de recuperação, zonas de busca e resultados de pesquisa) conteúdo e tarefas (cabeçalhos, links, metadados, pedaços de conteúdo, listas, ajudas sequenciais e identificadores) e métodos invisíveis (vocabulários controlados e tesauro, algoritmo de recuperação, melhores resultados).

O capítulo 6, identificado como Sistemas de Organização, descreve as formas de estruturar e organizar sites para atender às metas de negócios e às necessidades do usuário. Para os autores, a compreensão do mundo é informada pela forma como as coisas são classificadas, tarefa não tão fácil. Para classificar é necessário lidar com a ambiguidade, a heterogeneidade, as diferenças nas perspectivas e a política interna, dentre outros desafios. A organização do ambiente informacional é fator determinante para o seu sucesso. É possível organizar as coisas usando esquemas exatos de organização (alfabético, cronológico e agrupamentos geográficos) ou esquemas ambíguos (tópicos, orientados a tarefas, baseadoemaudiência, dirigido a metáforas) eagrupamentos híbridos. A estrutura dos esquemas de organização também desempenha um importante papel no design de ambientes de informação, podendo ser representada de forma hierárquica (abordagem Top-Down), modelo de banco de dados - base relacional (abordagem Bottom-Up) e hipertexto. Rosenfeld, Morville e Arango (2015) afirmam que a classificação social (social tagging) por meio de marcadores, advindos da experiência digital dos indivíduos nas redes sociais, é uma ferramenta relevante para organizar informações em As digitais compartilhadas. A combinação de diversas estruturas de organização pode criar um sistema de organização coeso.

No capítulo 7, Sistemas de Rotulagem, são apresentadas as abordagens para a criação consistente e efetiva de rótulos descritivos para um site. O ser humano rotula as coisas o tempo todo. A rotulagem é a maneira mais óbvia de mostrar a nossa organização de esquemas em vários sistemas e contextos. Um ambiente de informação serve como um intermediário que traduz lentamente mensagens a partir do sistema para os usuários, cujo feedback (quando ocorre) não acontece de modo imediato. Para minimizar esta problemática é fundamental criar rótulos que representem a realidade vivenciada pelos usuários de determinado ambiente virtual refletindo, ao mesmo tempo, o seu conteúdo. Os rótulos textuais são os mais comuns e incluem links contextuais, cabeçalhos, opções de sistema de navegação e termos de indexação. Os rótulos iconográficos são menos comuns, mas a adoção generalizada de dispositivos com menor 
espaço na tela determina sua relevância em muitos ambientes de informação ${ }^{10}$. Os autores indicam que a criação de etiquetas é um dos aspectos mais difíceis da $\mathrm{Al}$, pela ambiguidade da língua. Sempre há sinônimos e homônimos com que se preocupar e diferentes contextos influenciam a compreensão das pessoas. A consistência é apontada como uma das características deste sistema, que pode ser afetada pelos seguintes problemas: estilo, apresentação, sintaxe, granularidade, abrangência e audiência. Como recursos do sistema de rotulagem são apresentados: ambiente de informações atuais; ambientes comparáveis e competitivos; vocabulários controlados e tesauros. Existem várias fontes de inspiração, como um ambiente de informação existente e registo de análise de pesquisa, que podem ajudar a informar as opções de rotulagem.

Em Sistemas de Navegação, capítulo 8, os autores exploram o design de sistemas de navegação que auxiliam os usuários a entender onde eles estão e onde eles podem ir em um ambiente virtual e afirmam que este é um dos mais eficazes pilares da Al. Os sistemas de navegação são usados para traçar o curso, determinar a posição e encontrar o caminho de volta. Eles fornecem um senso de contexto e conforto na exploração de novos lugares. A camada superficial da navegação - onde as pessoas realmente interagem - muda constante e rapidamente. Os autores destacam como os três tipos mais comuns de sistemas de navegação: os sistemas globais, os locais e os contextuais ${ }^{11}$. As ferramentas usadas para explorar ambientes informacionais, como browsers, fornecem seus próprios mecanismos de navegação. A construção de contextos - que permite aos usuários localizarem suas posições dentro do sistema - é uma função crítica dos sistemas de navegação. Os sistemas de navegação global destinam-se a estar presentes em cada página ou tela no ambiente de informações. Os sistemas locais complementam os globais e permitem aos usuários explorar a área imediata onde estão. Os sistemas de navegação contextuais ocorrem no contexto do conteúdo sendo apresentado no ambiente e comportam aprendizagem associativa, permitindo que os usuários explorem o relacionamento entre itens. Como sistemas de navegação suplementares ${ }^{12}$ são apontados os mapas de site, índices, guias, configuração e pesquisa. A

10 Vidotti, Cusin e Corradi (2008) apresentam uma subdivisão semelhante à de Rosenfeld, Morville e Arango (2015) quanto aos tipos comuns de rótulos: textual (navegação - links, termos de indexação e cabeçalhos) e iconográfico (navegação e cabeçalhos).

11 Vidotti, Cusin e Corradi (2008) classificam os tipos mais comuns de sistemas de navegação como hierárquico, global e local e ainda, apontam como elementos integradores a estes a barra de navegação (gráfica e textual), os frames (estado real da tela, modelo da página, velocidade da página e projeto complexo) e menus (Pull-Down - clicar um item e Pop-Up - mover o cursor).

12 Também chamados de remotos por Vidotti, Cusin e Corradi (2008), os elementos suplementares são subdivididos em: tabela de conteúdo, index - índices e mapa de site. 
personalização e customização; a visualização e a navegação social são descritas e exemplificadas como abordagens de navegação avançadas.

Os componentes dos sistemas de busca, a descrição das abordagens para a indexação e o desenho de resultado das interfaces de pesquisa, a fim de melhorar o desempenho geral de um sistema permitindo que as pessoas encontrem o que estão procurando em ambientes informacionais são tratados no capítulo 9, denominado Sistemas de Busca (buscadores). A busca é um mecanismo importante para encontrar a informação. Apesar de parecer um processo simples, muita coisa acontece neste sistema para que o serviço seja realizado. Para definir se determinado produto necessita de um sistema de busca os autores lançam algumas reflexões como: quantidade de conteúdo no ambiente da informação, foco em sistemas de navegação mais úteis, tempo e know-how para otimizar o sistema de busca, outras alternativas, formas preferenciais de interação dos usuários, busca de auxílio diante de um grande volume de informação para navegar, busca de auxílio em sites fragmentados, pesquisa como ferramenta de aprendizagem (devendo estar disponível uma vez que os usuários esperam que ela esteja lá) e pesquisa orientada ao dinamismo. Os elementos que compõem a anatomia básica de sistema de busca são os autores, o conteúdo, o motor de busca, a interface (consulta, resultado) e os usuários. Um passo importante ao se configurar o sistema de busca é a escolha do que indexar de um ambiente informacional. As zonas de busca (tipo de conteúdo, audiência, função, assunto/tópico, geografia, cronologia, autor, departamento/unidade de negócios) são subconjuntos destes ambientes indexados separadamente do resto do conteúdo. Existem variados e diferentes algoritmos de busca, bem como formas variadas de se apresentar os resultados de uma pesquisa ao usuário. Todos esses fatores - o que procurar, o que recuperar e como apresentar os resultados - figuram na interface de pesquisa. Como ferramentas de buscas que visam facilitar a recuperação pelo usuário, os autores destacam: os corretores ortográficos, a busca fonética, a truncagem, o processamento da linguagem natural, o vocabulário controlado e o tesauro ${ }^{13}$. Como recursos de visualização são indicadas as listagens de resultados organizadas de forma alfabética; cronológica; ranking por relevância, popularidade, avaliação de usuários e especialistas e de posicionamento (pago) ${ }^{14}$. Para auxiliar os usuários quanto ao que fazer com os resultados de busca são apontados os mais

13 Vidotti, Cusin e Corradi (2008) dividem os tipos de busca por item conhecido, ideias abstratas, exploratória e compreensiva e quantos aos recursos de busca apontam a lógica booleana, a linguagem natural, os tipos específicos de itens e os operadores de proximidade.

14 Como recursos de visualização do sistema de busca, Vidotti, Cusin e Corradi (2008) citam listagens (ordenadas), relevância e refinamentos de busca. 
comuns, como: convite para ação, seleção de subconjuntos de resultados e opção de salvar a pesquisa. Quanto ao design de interface de pesquisa são indicadas algumas variáveis, como: nível de motivação e conhecimento para a busca, tipo de informação demandada e tipo/quantidade de informação pesquisada. Também são tratados neste capítulo questões referentes à caixa de busca, serviço autocomplete e autossugestão, pesquisa avançada, apoio a revisão (repetição de pesquisa na página de resultados, explicação da origem dos resultados, explicação referente ao que fazer, integração da pesquisa com a navegação), dentre outros.

A busca de soluções para melhorar a experiência dos usuários em sistemas de pesquisa e o modo como o controle do vocabulário pode conectar estes sistemas são apresentados no capítulo 10, intitulado Tesauro, vocabulários controlados e metadados. Os tesauros, vocabulários controlados e metadados operam no interior de um ambiente de informação, permitem a visualização de uma rede de relações entre sistemas, bem como uma experiência de sucesso na interface. Os metadados são dados que fornecem os meios de criação dos dados, sua finalidade, data e hora de criação, autoria, localização e padrões utilizados para descrever documentos, páginas, imagens, software, arquivos em áudio e vídeo e outros objetos de conteúdo para uma navegação melhorada e recuperação. Os vocabulários controlados são subconjuntos de linguagem natural que incluem sinônimos, arquivos de autoridade, esquemas de classificação e tesauros, organizados em forma de listas de termos equivalentes (sinônimo ou termos preferenciais). Um tesauro lista palavras em grupos de sinônimos e conceitos relacionados, ou seja, é uma rede semântica de conceitos que conecta as palavras para seus sinônimos, homônimos, antônimos, termos genéricos e específicos e termos relacionados. Seu objetivo mais importante é gerenciar para que ambiguidades não impeçam as pessoas de encontrar o que desejam, a partir das relações de equivalência, hierárquicas e associativas. Estes sistemas (tesauros e vocabulários controlados) permitem que a linguagem seja estruturada e mapeada, para que as pessoas possam encontrar as informações facilmente. Ao trabalhar com estes instrumentos é fundamental conhecer a terminologia utilizada pelos especialistas da área, garantindo a especificidade e eficiência da linguagem técnica adotada pelos pares. O cerne terminológico inclui termo preferencial, termos não preferenciais, termo genérico, termo específico, termo relacionado, use, usado por e nota de alcance. Existem três tipos de tesauros: clássico, de indexação e de busca, que variam conforme sua aplicação. A variedade de relações semânticas é a característica que diferencia um tesauro de um vocabulário controlado. Finalizando esta parte, os autores afirmam que a classificação facetada e a relação poli-hierárquica são 
instrumentos que permitem que a informação fique disponível em mais de uma maneira, possibilitando que as pessoas encontrem suas próprias rotas para o que estão procurando.

Os capítulos da última parte do livroAplicação da Arquitetura da Informação (parte 3), abrangem as ferramentas, técnicas e métodos conceituais aplicadas desde a estratégia e design de pesquisa à implementação de uma Al. O capítulo 11, Pesquisa, explica o processo de descoberta necessário para se criar uma base de entendimento para sua Al. Uma boa pesquisa significa fazer as perguntas certas e escolher as questões certas para requer um quadro conceitual de um ambiente mais amplo. O processo de desenvolvimento da Al engloba inúmeras etapas: pesquisa (o quadro conceitual conteúdo/contexto/usuários é usado como base de investigação), estratégia (definição dos níveis de organização do ambiente informacional e suas estruturas de navegação), design (criação do mapa do site, desenho básico e esquemas de metadados), implementação (organização e marcação de documentos, testes e resolução dos problemas de desenvolvimento) e gestão (avaliação contínua, identificação de melhorias a partir do feedback do usuários). O diagrama dos três círculos (contexto, conteúdo, usuários) contribui com uma abordagem equilibrada de pesquisa. Ao pesquisar o contexto, busca-se entender os objetivos, orçamentos, cronogramas, infraestrutura tecnológica, recursos humanos, cultura corporativa, questões legais e políticas, fatores que podem e devem interferir na forma da estratégia da Al. As ferramentas e métodos para pesquisar o contexto são pesquisa de base, apresentações e reuniões, entrevistas com as partes interessadas e avaliação de tecnologia. O conteúdo é definido como "material no ambiente de informação", que inclui dados, documentos, aplicações, serviços, imagens, páginas web, e-mails etc. As técnicas e ferramentas utilizadas para o desenvolvimento de projetos nesta vertente (conteúdo) são: avaliação heurística, análise de conteúdo, mapeando o conteúdo, benchmarking (medições comparativas e julgamentos) e, por fim, os usuários, também chamados de visitantes, entrevistados, clientes, contabilizados por cliques, impressões, vendas - juízes finais do ambiente informacional digital. Para conhecer melhor o usuário e suas necessidades, suas prioridades e seus modelos mentais é necessário observá-lo a partir de múltiplas lentes. Como premissa deve-se aplicar a regra fundamental da engenharia da usabilidade: qualquer teste é melhor que nenhum teste. Os usuários são os aliados mais poderosos. A pesquisa do usuário é um instrumento político, extremamente eficaz, que pode ser realizado por meio de técnicas como análise de uso (logs e clicks), estudos de caso (uso e pessoas), grupo focal, investigação contextual, card sorting e entrevistas e testes de usuários. 
No capítulo 12, denominado Estratégia, os autores apresentam uma estrutura e uma metodologia para se definir a direção e o alcance da Al. Uma estratégia de Al serve como uma ponte entre a pesquisa e o design. Ela fornece uma estrutura conceitual de alto nível para estruturar e organizar um ambiente de informações. Dentre as recomendações para estratégia de Al, destacamse: a administração da Al (política, estrutura departamental e propriedade de conteúdo), integração da tecnologia (oportunidade para alavancar ferramentas existentes e identificar a necessidade de tecnologias adicionais para desenvolver e gerenciar a Al), ênfase Top-Down e Bottom-Up (foco no status atual do produto, ambiente político e modelo de gestão da Al), sistema de organização e de rotulagem - Top-Down (identificação dos principais modos de organização do ambiente e identificação do esquema de organização dominante para servir como hierarquia primária), tipo de identificação do documento - Bottom-Up (identificação do conjunto de documentos e objetos requerendo colaboração entre o autor do conteúdo e a equipe de gerenciamento), definição dos campos de metadados (definição administrativa, estrutural e dos campos de metadados descritivos), design do sistema de navegação (definição de como os sistemas de navegação integrado e complementar irão alavancar as estratégias Top-Down e Bottom-Up. Antes de uma pesquisa começar, devem ser consideradas possíveis estratégias para estruturação e organização do produto. As hipóteses são testadas e refinadas durante a fase de investigação, durante as entrevistas com os usuários, análise de conteúdo e estudo de benchmarking. A transição da investigação para a estratégia envolve o equilíbrio entre o processo (pensar, articular, comunicar e testar) e o produto. Uma estratégia de Al pode ser comunicada por meio de metáforas, cenários, estudo de casos e histórias, diagramas conceituais, mapas de site e desenhos gráficos. Quanto aos entregáveis, os autores como fases estratégicas: o relatório de estratégia da Al, a apresentação da estratégia e o plano do projeto para design, sendo o relatório o principal produto concreto que precisa ser discutido com as partes interessadas.

Os resultados e processos necessários para aplicar a $\mathrm{Al}$ na vida cotidiana são apresentados no último capítulo do livro, intitulado Projeto $e$ documentação. Na fase de projeto, a ênfase se move do processo para a entrega - onde a Al começa a se manifestar. O processo é tão importante durante esta fase, como durante a pesquisa e a estratégia. Como as Al são abstratas e conceituais, torna-se um desafio capturá-las em diagramas. Para exibir seus diferentes aspectos, devem ser fornecidas várias "visões" de sua arquitetura, considerando públicos específicos. Para documentar a Al, os autores apontam algumas recomendações, como fornecer vários pontos de vistas de uma Al considerando a complexidade dos ambientes informacionais e desenvolver 
comunicações visuais para públicos e necessidades específicas. Os diagramas Al definem os componentes de conteúdo e as conexões entre eles, sendo os mapas de site e os wireframes os mais comuns. Os mapas de site mostram as relações entre elementos de informação, como páginas de conteúdo e outros componentes e podem ser utilizados para retratar organização, navegação e sistemas de rotulagem, enquanto os wireframes (desenhos gráficos) descrevem como uma página ou modelo deve partir de uma perspectiva arquitetônica. O mapeamento do conteúdo detalhado envolve a quebra ou a combinação do conteúdo existente em partes que são úteis para a inclusão no ambiente informacional e a modelagem do conteúdo auxilia a navegação contextual que funciona no interior do produto, proporcionando benefícios como a determinação do conteúdo mais importante a ser modelado e a definição dos atributos de metadados serão os únicos que farão com que o conteúdo seja um modelo operacional. Há dois produtos associados com o desenvolvimento de vocabulários controlados, aqueles transportados com matrizes e aplicações de metadados que permitem que o vocabulário seja gerido e a ferramenta necessária para gerenciar os termos e as relações dos vocabulários. A colaboração é maior com as pessoas envolvidas no desenvolvimento de produtos - mente aberta e boas ferramentas de colaboração são instrumentos essenciais para elaboração do projeto.

Considerando a dimensão da Web e as potenciais e radicais formas de publicação e navegação de informações, novas abordagens foram necessárias para torná-la fácil de se usar e entender. Na seção denominada Coda ${ }^{15}$, os autores compartilham a evolução e o aprofundamento na temática (AI) conquistada nestes quase 20 anos de investigação, desde a publicação da primeira edição, fazendo analogia às fases da vida: infância (perspectivas de um vasto novo mundo a ser explorado), pré-adolescência (desafios da arquitetura no contexto dos sistemas existentes), adolescência (desafios e oportunidades inerentes orientada socialmente a mais ambientes de informação) e fase adulta (honraria ao passado, reformulando o conhecimento acumulado no livro desde a primeira edição de modo que possa atender melhor às necessidades humanas do presente e do futuro imediato).

Nesta quarta edição foram introduzidos os desafios que a Al pode ajudar a resolver, como a sobrecarga de informações, a proliferação contextual e a reflexão sobre os produtos e sistemas projetados para ambientes de informação ou lugares feitos de informação. Como os usuários interagem com esses

15 Termo originário da Itália que significa cauda, "parte final de um trecho de música, na qual, em regra, se recordam os temas fundamentais." (CODA, 2003-2016). No contexto da obra resumida referese a uma seção conclusiva. 
ambientes de informação em vários contextos distintos, utilizando diferentes canais de acesso, sua experiência precisa ser coerente. A fim de tornar isso possível, os arquitetos da informação precisam pensar em possíveis soluções de forma abrangente. Como parte de um sistema e como resultado busca-se uma informação que seja mais fácil de ser encontrada e compreendida.

Por meio dos princípios básicos da Al é possível estruturar a informação visando melhor encontrabilidade e inteligibilidade. Foram discutidas maneiras diversificadas de organizar ambientes de informação, incluindo esquemas de organização exatos e ambíguos, hierarquias, bases de dados estruturadas e sistemas de hipertexto de forma livre. Os autores também destacaram a importância da rotulagem: palavras utilizadas pelas pessoas, em forma de links, títulos, entre outras e os vários tipos de sistemas de navegação e busca, incluindo os sistemas "invisíveis" que o usuário não percebe diretamente, tais como os metadados, os esquemas de classificação facetado etc.

O processo de concepção de uma Al agrega todos esses princípios, que se dissipam por meio da pesquisa (compreensão do problema a ser resolvido), estratégia (sintetização de uma solução abrangente) e projeto e documentação (compartilhamento de solução aos responsáveis pela produção do ambiente de informação). Para os autores, este conteúdo particular não se esgota com a publicação desta obra. A Al é uma temática que tem a vantagem de evoluir ao longo do tempo para responder à mudança das necessidades dos designers, dos usuários e, no contexto mais amplo da prática, acompanhar a evolução dos ambientes de informação complexos.

A tecnologia ocupa cada vez mais espaço na vida das pessoas. Apesar de estarem fisicamente em determinado ambiente, a maioria das pessoas está com a mente em outro lugar. Elas são participantes temporárias de ambientes informacionais compartilhados, acessados por meio das telas sensíveis ao toque (Touch Screen). Este é um vasto mundo novo, esperando para ser explorado. Neste contexto, os autores alertam que apesar de não ser fácil transformar essas ideias abstratas em algo tangível, especialmente quando se trabalha em um ambiente dinâmico, cabe aos arquitetos da informação empregar as estratégias e táticas de Al de forma eficaz visando o bem comum de tornar a informação encontrável e compreensível.

Louis Rosenfeld é co-fundador do Instituto de Arquitetura de Informação, a única organização profissional dos arquitetos da informação e da Arquitetura de Informação Summit, conferência anual do campo. É também consultor sobre a estratégia de Al e administra a Rosenfeld Media, onde publica livros de experiência do usuário e oferece treinamento UX e consultoria. Lou tem participado intensamente nos esforços para se aglutinar a comunidade Al. Seu 
trabalho tem sido essencial para ajudar a estabelecer as áreas de Al e experiência do usuário, e também em articular o papel e o valor da biblioteconomia neste campo. Como um estudante de pós-graduação em Informação e Biblioteconomia na Universidade de Michigan no final de 1980, Lou convenceuse de que as competências dos bibliotecários foram subvalorizadas. À medida que a Web começou a explodir, Lou percebeu que as habilidades e perspectivas adicionais foram necessárias para desenvolver, estruturas intuitivas coerentes - arquiteturas de informação - que fizeram o conteúdo web acessível aos utilizadores. No Argus Associates, empresa de consultoria pioneira que cofundou em 1991, Lou introduziu perspectivas adicionais, como engenharia de usabilidade, etnografia, análise de tecnologia e outros (inovações de sucesso) que permitiram que a empresa se tornasse talvez a empresa mais conhecida no campo da Al. Com a explosão informacional, quem mais poderia fornecer as habilidades de organização, classificação e rotulagem de informações? Para testar sua teoria, em 1993, Lou fundou um serviço de pesquisa de internet popular, o Argus Câmara, onde demonstrou como a biblioteconomia poderia contribuir para tornar o conteúdo baseado em uma internet mais acessível. Neste mesmo período ele criou e ministrou alguns dos primeiros cursos acadêmicos sobre a criação de informação para uso na Internet. Lou foi presidente da Argus de 1994-2001 e nomeado "Pioneiro da Tecnologia" por Crain Detroit Business. Foi consultor de organizações como Paypal, Accenture, AT \& T, Caterpillar, Lowes, os Centros de Controle de Doenças, Ford e Microsoft. Com Peter Morville, ele foi co-autor do best-seller, Arquitetura de Informação para a World Wide Web (O'Reilly, 1998; 2. ed., 2002; 3. ed, 2006). O livro de 1998, Best Internet da Amazon. com, com mais de 250.000 em vendas, tem sido aclamado como um clássico e é usado como um texto padrão em muitos cursos de pós-graduação. Em 2011 publicou o livro Análise de pesquisa para o seu site, publicado pela Rosenfeld Mídia. Lou contribui com colunas regulares para $\mathrm{CIO}$, Internet Mundial e revistas Web revisão. Escreveu e editou inúmeros livros, capítulos e artigos acadêmicos. (Louis, 2016; Rosenfeld Media, 2016).

Como Rosenfeld, Peter Morville é um dos pioneiros dos campos de Al e experiência do usuário. É conhecido como uma figura influente e «pai fundador» da Al, sendo co-autor dolivro mais vendido naárea, Arquitetura de Informação para a World Wide Web. Foi co-fundador e ex-presidente do Instituto de Arquitetura de Informação e tem servido em seu conselho consultivo. Nascido em Manchester, na Inglaterra, Peter também possui pós-graduação em Biblioteconomia e Ciência da Informação (Cl) pela Universidade de Michigan School of Information (1993). Desde então, tem servido em sua faculdade e recebeu um prêmio de mérito Alumni por seu trabalho em Cl. Junto com Louis Rosenfeld dirigiu a Argus 
Associates, empresa de consultoria que apoiou um dos precursores do Instituto de Arquitetura de Informação, o Centro de Argus para a Arquitetura de Informação. Peter Morville é presidente da Semantic Studios, uma empresa de Al e consultoria em Findability. Suas obras têm influenciado uma geração de profissionais e organizações. Seu modo de falar e escrever traz a consciência focalizada para longo alcance dos problemas de informação, de tal forma que auxilia as pessoas a tomar medidas práticas. Seus livros mais vendidos incluem Arquitetura de Informação para a World Wide Web (1998), Ambient Findability (2005), Padrões de Pesquisa (2010) e Intertwingled: a informação muda tudo (2014). Para mais de uma década, aconselhou os clientes como AT\&T, Cisco, Harvard, IBM, Marcy, Vodafone, Dow Chemical, Ford, FMI, Biblioteca do Congresso, Instituto Nacional do Cancer e Microsoft. Proferiu palestras, conferências, seminários e workshops em eventos internacionais na América do Norte, América do Sul, Europa, Ásia e Austrália. Seu trabalho tem sido destaque nas principais publicações incluindo a Business Week, NPR, The Economist, The Washington Post, Fortune e The Wall Street Journal. (Peter, 2016; Semantics Studios, 2016).

Jorge Arango é um arquiteto de informação (designer) da primeira geração, com mais de 20 anos de experiência em produtos e serviços digitais. É parceiro no Futuredraft, uma consultoria de design digital com sede em Oakland, CA, e tem servido a comunidade global UX como presidente e diretor do Instituto de Arquitetura de Informação e como editor da revista caixas e setas. Dentre seus trabalhos na área, destacam-se: Arquitetura de Informação: Design for Understanding e a co-autoria com Rosenfeld e Morville, na 4a edição do livro Information Architecture: for the Web and beyond, obra que explora como a Al infunde produtos com significado e um senso de lugar. Como designer, Jorge visa produzir ambientes de informação que ajudam as pessoas a entender e interagir com seu mundo de forma mais eficaz (Jarango, 2016).

\section{REFERÊNCIAS}

CODA. In: DICIONÁRIO da Língua Portuguesa com Acordo Ortográfico. Porto: Porto, 2003-2016. Disponível em: http://www.infopedia.pt/dicionarios/linguaportuguesa/coda. Acesso em: 6 jul. 2016.

JARANGO. Jorge Arango. 2016. Disponível em: https://jarango.com/. Acesso em: 31 jun. 2016.

LOUIS Rosenfeld. In: WIKIPEDIA: The Free Encyclopedia. 2016. Disponível em: https:// en.wikipedia.org/wiki/Louis_Rosenfeld. Acesso em: 31 jun. 2016.

PETER Morville. In: WIKIPEDIA: The Free Encyclopedia. 2016. Disponível em: https:// 
en.wikipedia.org/wiki/Peter_Morville. Acesso em: 31 jun. 2016.

ROSENFELD MEDIA. Louis' Biography. 2016. Disponível em: http://rosenfeldmedia. com/expert/louis-rosenfeld/. Acesso em: 31 jun. 2016.

SEMANTIC STUDIOS. Peter Morville'S Biography. Michigan, 2016. Disponível em: http://semanticstudios.com/about/. Acesso em: 31 jun. 2016.

VIDOTTI, Silvana Aparecida Borsetti Gregório; CUSIN, Cesar Augusto; CORRADI, Juliane Adne Mesa. Acessibilidade digital sob o prisma da Arquitetura da Informação. In: GUIMARÃES, J. A. C.; FUJITA, M. S. L. (Orgs.). Ensino e pesquisa em Biblioteconomia no Brasil: a emergência de um novo olhar. São Paulo: Cultura Acadêmica, 2008. p. 173-184.

Recebido em: 18/02/2018

Aceito em: 22/03/2018

Dados das autoras:

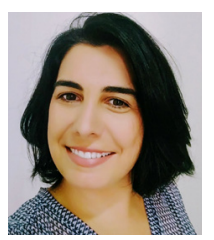

Angela Maria Grossi de Carvalho|angela@carvalho.jor.br

Universidade do Estado de São Paulo

Pós-doutora em Comunicação, pela Universidade de Sevilha, Sevilha, Comunidade Autónoma de

Andaluzia, Espanha. Docente do Programa de Pós-Graduação em Ciência da Informação da Unesp, Marília,

SP e do curso de Jornalismo da Unesp, Bauru, SP.

Endereço da autora:

Universidade Estadual Paulista Júlio de Mesquita Filho (Unesp)

Bauru - Faculdade de Arquitetura, Artes e Comunicação (FAAC)

Av. Eng. Luiz Edmundo Carrijo Coube, 14-01

Bairro Vargem Limpa

17.033-360 - Bauru/SP

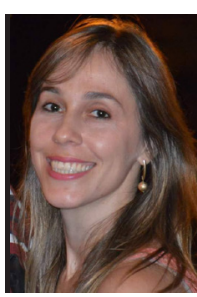

Maira Nani França | mairanani@hotmail.com

Universidade Estadual Paulista Júlio de Mesquita Filho

Doutoranda do Programa de Pós-Graduação em Ciência da Informação (PPGCI) da Universidade Estadual

Paulista Júlio de Mesquita Filho (Unesp), Marília, SP. Bibliotecário-Documentalista, Universidade Federal de Uberlândia, Sistema de Bibliotecas (UFU/SISBI), Uberlândia, MG.

Endereço da autora:

Universidade Federal de Uberlândia, Sistema de Bibliotecas (UFU/SISBI)

Av. João Naves de Ávila, 2121 - Bloco 3C

Bairro Santa Mônica

38.400-902 - Uberlândia/MG

Contribuições das autoras: Ambas as autoras fizeram contribuições substanciais para concepção, desenvolvimento, redação e revisão crítica do trabalho; e aprovação final da versão para publicação. 